\title{
Comunicação e movimentos sociais: a atuação do Fórum Nacional pela Democratização da Comunicação na internet
}

Communication and social movements: the activities of the National Forum for Communication Democracy on the internet

Comunicación y movimientos sociales: la actuación del Foro Nacional para la Democratización de la Comunicación en internet

Caroline Kraus Luvizotto

- Doutora, mestre e bacharel em Ciências Sociais pela Universidade Estadual Paulista (Unesp)

- Docente do Programa de Pós-Graduação em Comunicação da Unesp - Bauru

- Líder do grupo de pesquisa Comunicação Midiática e Movimentos Sociais (ComMov)

- Foi coordenadora do Mestrado em Educação da Universidade do Oeste Paulista (Unoeste)

- E-mail: caroline@faac.unesp.br

Natália dos Santos Gonzales

- $\quad$ Mestranda em Comunicação na Universidade Estadual Paulista (Unesp) - Bauru

- Especialista em Comunicação Organizacional pela Universidade Metodista de São Paulo (Umesp)

- Graduada em Relações Públicas pela Unesp - Bauru

- E-mail: nataliagonzales.rp@gmail.com

\section{Renata Calonego}

- Mestranda em Comunicação na Universidade Estadual Paulista (Unesp) - Bauru

- Graduada em Relações Públicas pela Unesp - Bauru

- Membro do grupo de pesquisa Relações Públicas e Comunicação: Opinião Pública, Educação e Interculturalidade

- E-mail: rcalonego@gmail.com 


\section{Resumo}

A partir do exemplo do Fórum Nacional pela Democratização da Comunicação (FNDC) e de sua ação nas redes sociais online, este artigo tem como objetivo refletir sobre a importância da internet e das redes sociais para a mobilização social, para a organização, a disseminação e o fortalecimento dos movimentos sociais e dos ativistas. Apesar de 0 FNDC não utilizar toda a potencialidade das redes sociais online, conclui-se que estas têm papel fundamental para 0 fortalecimento dos mais diferentes movimentos sociais.

\section{PALAVRAS-CHAVE: COMUNICAÇÃO・MOVIMENTOS SOCIAIS・REDES SOCIAIS ONLINE・FNDC.}

\section{Abstract}

Based on the example of the National Forum for Communication Democracy (FNDC) and its action on online social networks, this article aims to consider the importance of the internet and social networks for social mobilization, organization, dissemination and strengthening of the social movements and activists. Although the FNDC does not use the whole potential of online social networks, it is verified that they have a crucial role in strengthening diversified social movements.

\section{KEYWORDS: COMMUNICATION • SOCIAL MOVEMENTS•ONLINE SOCIAL NETWORKS・FNDC.}

\section{Resumen}

A partir del ejemplo de FNDC - Foro Nacional por la Democratización de laComunicación (FNDC) y suacción en las redes sociales online, este artículo tiene como objetivo reflexionar sobre la importancia de internet y las redes sociales para la movilización social para la organización, la difusión y el fortalecimiento de los movimientos y activistas sociales. A pesar de que el FNDC no utiliza todo el potencial de las redes sociales online, se llegó a la conclusión de que tienen un papel fundamental para el fortalecimiento de los diferentes movimientos sociales. 


\section{ANO 14 • NÚMERO 26 • 1으 SEM. 2017 - ORGANICOM COMUNICAÇÃO E MOVIMENTOS SOCIAIS: A ATUAÇÃO DO FÓRUM NACIONAL PELA DEMOCRATIZAÇÃO DA COMUNICAÇÃO NA INTERNET}

0

s recursos e as tecnologias foram aprimorados rapidamente, democratizando de maneira inédita 0 acesso à informação. Com o advento da internet e das ferramentas da web 2.0, a informação deixa de se concentrar na mídia de massa e nos grandes conglomerados midiáticos e se oferece a possibilidade de produção, seleção e interação aos seus usuários, gerando novos conteúdos e fontes de informação. Hoje, ONGs, movimentos sociais e ativistas podem propagar suas ideias para todo o mundo, oferecendo a informação à sua maneira. Agências de notícias alternativas e independentes surgem para contestar as versões da imprensa tradicional, como é o caso da mídia Ninja, Jack Mídia Independente e diversos blogues e websites contra-hegemônicos (Luvizotto, 2016).

Presenciamos o fenômeno da multiplicação de manifestações quase virais de comunicação, que se expandem continuamente, com o processo de informatização e digitalização dos canais e das ferramentas de comunicação, e acabam desencadeando 0 rápido aumento do número de internautas e de comunidades virtuais desterritorializadas e até multiculturais. A profusão na internet de novos nichos de público alimenta a progressão global dos volumes e da diversidade de conteúdos informativos, de interação social e de entretenimento. Muitas mensagens e produtos multimidiáticos são produzidos de forma colaborativa pelas redes de ativistas, ou até mesmo pela ação coletiva de diletantes, que vão compartilhando continuamente tudo o que produzem, reinterpretam ou de que se apropriam, sem se preocupar com a propriedade ou a origem de cada informação.

As ferramentas web 2.0 estão organizand o e fomentando o desenvolvimento de novas mídias digitais e redes sociais virtuais, à medida que são reduzidos os custos da mobilização de atores sociais. A ação política através das tecnologias "torna-se mais barata, rápida e por consequência mais acessível a grupos que não fazem parte do sistema político institucionalizado", segundo Pereira (2011, p. 14). As redes que integram essa lógica possuem potencial articulador e mobilizador e, segundo Scherer-Warren (2006, p. 115), "por serem multiformes, aproximam atores sociais diversificados - dos níveis locais aos mais globais, de diferentes tipos de organizações - e possibilitam o diálogo da diversidade de interesses e valores".

Os recursos da web 2.0 facilitaram a criação e a circulação de conteúdos aos usuários da internet, que podem atuar como leitores, autores, produtores e editores de conteúdo informacional multimidiático. 0 usuário não é mais pensado como agente passivo, mas como desenvolvedor de conteúdo. A web 2.0 é considerada a segunda geração de ferramentas online, caracterizada pelas mídias digitais que potencializam as formas de publicação, compartilhamento e organização de informações, além de expandir os espaços para a colaboração entre os participantes. Essa tecnologia reforça a promessa de criação de inteligência coletiva (Lévy, 1994) ou construção coletiva do conhecimento. Por meio da interação, comunidades formadas em torno de interesses específicos poderão apoiar uma causa, discutir temas individuais ou de relevância coletiva, levar a opinião pública à reflexão e disseminar informações políticas e sociais (Valente; Mattar, 2007). Com as tecnologias de informação e comunicação (TIC) espera-se, de acordo com o seu potencial, disseminar os conteúdos informacionais com o máximo de intercâmbios, buscando a interação, o apoio, as críticas, as sugestões que, no caso do ativismo social, se traduzem em expressar por meio de seus atores, da forma mais diversa e abrangente possível, a luta pela concretização da cidadania (Moraes, 2000).

0 ativismo na internet é um fenômeno constatado por diversos pesquisadores (Peruzzo, 2013; Gohn, 2007; Castells, 2013), que descrevem as ações desenvolvidas por vários movimentos sociais, sendo que estas acabam unindo, de modo simultâneo, ações de rua, passeatas, atos e protestos, com recursos de comunicação instantânea que difundem as reivindicações perante a população e também atuam como canais públicos para cobrar e pressionar diversas instâncias de governo. Nesse sentido, a partir do exemplo do FNDC - Fórum Nacional pela Democratização da Comunicação e sua ação nas redes sociais online, este artigo tem como objetivo refletir sobre a importância da internet e das redes sociais para a mobilização social, para a organização, disseminação e potencialização das ações dos movimentos sociais e dos ativistas. 
Para iniciar a reflexão, discorre-se acerca da importância da comunicação como agente de transformação social, destacando a importância da internet e das suas tecnologias web 2.0 para a participação política e social. Depois, descreve-se o FNDC, sua estrutura e suas características. Na sequência, apresenta-se um monitoramento das redes sociais online do FNDC, realizado no mês de maio de 2016, procurando identificar limites e potencialidades do seu ativismo online. Com a análise que se faz em seguida, pretende-se ampliar-se a compreensão dos mecanismos de difusão de informações e debate, fornecidos pelas redes sociais, a serviço dos movimentos sociais.

\section{A COMUNICAÇÃO COMO AGENTE DE TRANSFORMAÇÃO SOCIAL}

A sociedade contemporânea presencia uma fase de muitas transformações diante da globalização, da desterritorialização da informação, do conhecimento com as novas tecnologias das quais emergem novos paradigmas sociais, culturais, econômicos que, porém, acarretam problemas em todas as instâncias sociais. Como reflexo desse cenário, movimentos sociais, instituições privadas e organizações não-governamentais se movimentam em busca de minimizar mazelas dessa conjuntura da sociedade.

Diante desse contexto, a comunicação constitui-se como área essencial na promoção e consolidação da cidadania, por impulsionar as pessoas a se sentirem sujeitos dos seus direitos e, ainda mais, serem capazes de protagonizar mudanças em prol dos direitos da coletividade. "Assim, a relação entre comunicação e cidadania perpassa a disputa pela liberdade civil ou política e com os desdobramentos dos direitos inerentes a essas acepções" (Vicente, 2009, p. 86).

Exercer a cidadania remete a participar ativamente e com consciência do que acontece ao redor. A cidadania traduz 0 sentimento de pertencer a uma nação e à posse de direitos e deveres civis, políticos e sociais, e é por meio da comunicação que a população tem a possibilidade de ter mais consciência da importância da participação e de sua capacidade de exercê-la.

A participação é uma ação social coletiva que possui em sua gênese uma série de características, dentre as quais podemos destacar suas estratégias de ação, sua organização, a historicidade, os laços e as identidades compartilhadas. Essas características somadas a um projeto de sociedade é que levam os atores sociais a se aproximarem dessas ações coletivas e atuarem ativamente ou ocasionalmente junto aos movimentos sociais, aos espaços de deliberação política e aos mais diversos contextos onde se faz necessária uma ação democrática e cidadã (Luvizotto; Seridório, 2016).

A participação está intimamente ligada à cidadania e vai mudar de acordo com a possibilidade de atingir diferentes sujeitos sociais que se identificam com determinada causa, ou simplesmente têm consciência de seu papel como cidadãos e sentem a necessidade de participar. Segundo Bordenave (1983, p. 23), "participação é fazer parte, tomar parte ou ter parte". Para ele, de nada adianta "fazer parte"' sem "'tomar parte", como alguém que faz parte de um grupo mas não toma parte das decisões do grupo. A participação está ligada à atividade e ao engajamento. A participação seria inata ao ser humano devido às suas necessidades criativa e racional e a democracia seria um estado da participação (Bordenave, 1983).

Nesse sentido, Bandeira (2011) defende que é por meio da difusão de informação que temas às vezes restritos à esfera privada ganham destaque na esfera pública. A publicização torna-se então fundamental para o desencadeamento do debate público possível na comunicação compartilhada, que resultará em novas demandas sociais ao Estado.

A comunicação permeia essa conjuntura de diversas formas, entre as quais a que diz respeito à divulgação das ações das organizações que buscam melhorias para, na maioria das vezes, as comunidades mais vulneráveis. Uma das formas de as 


\section{ANO 14 • NÚMERO 26 • 1ํ SEM. 2017 - ORGANICOM COMUNICAÇÃO E MOVIMENTOS SOCIAIS: A ATUAÇÃO DO FÓRUM NACIONAL PELA DEMOCRATIZAÇÃO DA COMUNICAÇÃO NA INTERNET}

organizações realizarem melhorias diante dos problemas atuais é promover mobilizações sociais em busca de um objetivo comum. Para buscar a efetividade na comunicação de mobilizações sociais, o objetivo da mensagem precisa estar focado no impacto da comunicação e não somente em seu alcance quantitativo. Henriques e Mafra (2001) salientam que a mobilização, como um processo amplo, não depende, para ser bem-sucedida, apenas de simples difusão de informações, como muitos são levados a acreditar, muito embora a visibilidade, a divulgação e a presença na mídia sejam elementos importantes.

É necessário, em atividades que objetivam a mobilização de determinado público, que haja a interação com este público, por meio de uma comunicação dialógica, para que este se sinta corresponsável pelos próximos passos do projeto e, por fim, se engaje ainda mais por determinada causa. De acordo com Henriques (2013), a comunicação no processo de mobilização é dialógica, pois não é somente uma transferência do saber e sim um encontro de sujeitos interlocutores. A coparticipação nessa comunicação é que torna o homem capaz de transformar a realidade que o cerca, sem invasão e a imposição unidirecional.

$\mathrm{Na}$ atualidade, as principais ações e movimentos sociais atuam por meio de redes sociais, locais, regionais e utilizam-se muito dos novos meios de comunicação, como a internet (Gohn, 2007). A possibilidade de comunicação rápida, de baixo custo e de grande alcance faz da Internet o principal instrumento de articulação e comunicação das organizações da sociedade civil, movimentos sociais e grupos de cidadãos.

Com a internet e as mídias digitais, as formas de comunicação e consumo de informação se modificaram, deixando de ser unilaterais - marca dos meios de comunicação de massa - e passam a ser mais participativas e democráticas. Mesmo que de maneira limitada, considerando os problemas de acesso a rede, acessibilidade, usabilidade e conhecimento do usuário, a internet possibilita participação e interação entre os indivíduos, sendo uma forma de comunicação rápida, prática e sem barreiras geográficas. Esse ambiente online modificou a maneira como sujeitos e grupos sociais manifestam as suas demandas políticas e sociais. Nesse contexto, surge o ativismo, que ganha espaço privilegiado na internet e a atuação dos movimentos sociais passa a ser mais abrangente ocupando os espaços online (na internet) e off-line (nas ruas) (Luvizotto et. al., 2016). Para ilustrar como ativistas e movimentos sociais se apropriam da internet e das redes sociais para tornar públicas as suas demandas, organizar ações e disseminar informação, apresenta-se a seguir o caso do FNDC.

\section{O FNDC - FÓRUM NACIONAL PELA DEMOCRATIZAÇÃO DA COMUNICAÇÃO E AS REDES SOCIAIS ONLINE}

O FNDC foi criado em julho de 1991 como movimento social, tornando-se uma entidade em 1995. Carrega em sua gênese a ideia de que a democracia no Brasil não pode existir sem a efetiva democratização dos meios de comunicação. Entre suas ações destaca-se a defesa da radiodifusão comunitária, da regulamentação da cabodifusão, da reforma da lei de imprensa e da criação de conselho de comunicação social do Congresso Nacional. 0 movimento também se dedica a denunciar a concentração midiática e a defesa de uma nova lei para regular a concessão de radiofusão pública, estando presente nos principais eventos que trazem como pauta a discussão sobre políticas públicas para o setor, o direito e a democratização da comunicação. Atualmente, o FNDC conta com 69 organizações nacionais filiadas e está organizado em comitês regionais em dezenove estados brasileiros. ${ }^{1}$

1 Informação disponível em< http://fndc.org.br/forum/entidades-associadas/>. Acesso em: 28 jun. 2016. 
Para atingir o objetivo proposto neste estudo, qual seja, refletir sobre a importância da internet e das redes sociais para a mobilização social, para a organização, disseminação e potencialização das ações dos movimentos sociais e dos ativistas, a partir do exemplo do FNDC, é importante considerar a conjuntura do país no momento das análises realizadas no presente estudo. Durante a primeira quinzena de maio de 2016, mês utilizado no monitoramento das redes sociais do FNDC, o vicepresidente Michel Temer havia assumido a presidência do país, devido ao afastamento da então presidenta Dilma Rousseff. Ao assumir a presidência, Michel Temer iniciou uma série de mudanças ministeriais, inclusive alterações no funcionamento da EBC - Empresa Brasileira de Comunicação, o que acarretou uma atuação bastante significativa do FNDC em suas mídias diante das notícias que envolviam tal temática.

0 início do governo Temer, em meados de 2016, foi mais um período turbulento na história da democracia brasileira, tendo sido possível acompanhar as respostas dos movimentos sociais frente ao retrocesso que viria com o desmonte da Empresa Brasil de Comunicação (EBC), proposta de Michel Temer na época. A atuação do FNDC na internet foi visivelmente alterada nos dias que se seguiam não só às decisões tomadas referentes ao campo da comunicação no Brasil, mas também ao próprio funcionamento do poder executivo. Pode-se perceber então, uma onda crescente de postagens e também compartilhamentos de eventos que aconteceriam em protesto contra essas medidas, que por vezes bateu a marca de mais de vinte posts em um único dia na página do FNDC no Facebook e no Twitter.

\section{METODOLOGIA DE PESQUISA}

A análise da atuação do FNDC na internet, em suas redes sociais, ocorreu durante o mês de maio de 2016. Para a realização do monitoramento foram criadas algumas categorias que pudessem colaborar para o desenvolvimento das análises, demonstradas a seguir. A coleta de material foi feita manualmente, por meio da observação, sem auxilio de software.

Como forma de acompanhamento das postagens nas mídias Facebook e Twitter, foi utilizado o recurso print screen para copiar as telas dos posts no final de cada semana do período da análise. Foram coletados 132 prints das postagens do Facebook e 159 do Twitter. A partir desses dados coletados, foi criada uma planilha com as seguintes informações de cada post. data, link de acesso, teor, assunto, linkassociado, formato, quantidade de curtidas, quantidade de compartilhamentos, quantidade de comentários, interação/resposta e uso de hashtags.

Na coluna "teor", as categorias criadas foram: notícia, divulgação, informativo e ativista. Tratando-se do formato, foram delimitadas as seguintes opções: link, texto, imagem, vídeo e gif. Para analisar o sitefoi necessário navegar pelo link "Notícias" presente na home do portal. Já no Youtube, foi feita a visita no canal do FNDC e v erificaram-se as últimas postagens.

Feito o levantamento dessas informações, a análise a seguir relaciona os dados encontrados com a teoria apresentada neste artigo.

\section{Facebook}

Ao final do mês de maio a fanpage do FNDC² possuía 16.289 curtidas. No Facebook, o fórum se define como uma organização que "luta por um país democrático onde todos tenham acesso à informação e à comunicação". No decorrer do mês de maio foram coletados 132 posts, somando mais de 4 mil curtidas e mais de 3 mil compartilhamentos. Durante a análise, percebeu-se

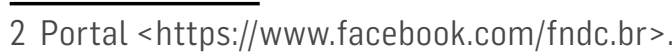


que não houve uma padronização na distribuição de posts durante a semana, alguns dias tiveram uma quantidade elevada de posts, enquanto em outros dias não havia a atualização da página. Adotou-se como padrão coletar os dados e realizar os prints das telas sempre no fim de cada semana. Na tabela a seguir destacam-se os posts que obtiveram mais curtidas durante o mês.

Tabela 1: FNDC - Posts mais curtidos no Facebook

\begin{tabular}{|c|c|c|c|c|c|}
\hline Data & Teor & Assunto & Formato & Curtidas & \# \\
\hline $02 / 05$ & $\begin{array}{l}\text { Divulgação; } \\
\text { Ativista }\end{array}$ & $\begin{array}{l}\text { FNDC e Frente Brasil popular convocam e } \\
\text { organizam ato contra o golpismo midiático. }\end{array}$ & $\begin{array}{l}\text { Texto; } \\
\text { Imagem; } \\
\text { Link }\end{array}$ & 89 & \#golpismodamída \\
\hline 05/05 & Ativista & $\begin{array}{l}0 \text { monopólio das comunicações é o } \\
\text { verdadeiro golpe na democracia! }\end{array}$ & $\begin{array}{l}\text { Texto; } \\
\text { Imagem }\end{array}$ & 81 & \#golpismodamída \\
\hline $12 / 05$ & $\begin{array}{l}\text { Informativo; } \\
\text { Ativista }\end{array}$ & $\begin{array}{l}\text { Dilma assina decreto que regulamenta } \\
\text { o Marco Civil da internet. }\end{array}$ & Link & 209 & - \\
\hline $17 / 05$ & Informativo & $\begin{array}{l}\text { Estadão recusa texto Wagner } \\
\text { Moura sobre o MinC. }\end{array}$ & Texto; Link & 92 & - \\
\hline 23/05 & Informativo & $\begin{array}{c}\text { Censura na EBC: Agência Brasil não } \\
\text { divulga escândalo de Jucá. }\end{array}$ & Texto; Link & 93 & - \\
\hline $25 / 05$ & $\begin{array}{l}\text { Informativo; } \\
\text { Ativista }\end{array}$ & $\begin{array}{l}\text { EBC suspende contrato de Paulo Moreira } \\
\text { Leite e desconvida senadora para entrevista. }\end{array}$ & Texto; Link & 90 & - \\
\hline $25 / 05$ & $\begin{array}{l}\text { Informativo; } \\
\text { Ativista }\end{array}$ & $\begin{array}{l}\text { Tereza Cruvinel, Paulo Moreira } \\
\text { Leite e Sidney Rezende deixam } \\
\text { EBC após quebra de contrato. }\end{array}$ & Texto; Link & 104 & - \\
\hline
\end{tabular}

Fonte: Os autores.

A análise sugere que a página fez pouco uso do recurso hashtag, que pode ser utilizado tanto para monitorar os seguidores que estão utilizando a hashtag em outras publicações, com tema similar, quanto para desenvolver ações/campanhas que busquem gerar uma alta disseminação por meio de determinada hashtag. Os posts com mais curtidas transitaram entre textos informativos e/ou conteúdos ativistas, porém verificou-se que os que obtiveram mais curtidas foram os que possuíam relação com polêmicas que envolviam a situação política do país naquele momento.

Na maioria das vezes o conteúdo foi postado com um texto de apoio sobre a notícia e, para se aprofundar no assunto, havia um link para uma notícia que poderia estar no site do FNDC ou, na maioria das vezes, em portais de notícias. Após o fim do monitoramento, percebeu-se que dois posts foram deletados, os realizados no dia 25/05. Os dois posts tinham assuntos 
semelhantes, dizendo respeito à suspensão do contrato de alguns diretores da EBC. Os posts tiveram grande repercussão até o momento em que foram monitorados.

A Tabela 2 ilustra os posts que obtiveram maior número de compartilhamentos durante o mês monitorado. Além das curtidas e compartilhamentos, percebeu-se uma baixa presença de comentários e quase nula interação da página com os comentários. Com isso, pode-se sugerir que, caso houvesse uma maior interação da página com os fãs, poderia haver um crescimento na utilização do espaço de comentários por partes dos que seguem a página.

Tabela 2: FNDC - Posts mais compartilhados no Facebook.

\begin{tabular}{|c|c|c|c|c|c|}
\hline Data & Teor & Assunto & Formato & $\begin{array}{l}\text { Comparti- } \\
\text { lhamentos }\end{array}$ & \# \\
\hline $02 / 05$ & $\begin{array}{c}\text { Informativo; } \\
\text { Ativista }\end{array}$ & $\begin{array}{c}\text { Mídia tem o papel de } \\
\text { domesticar população em } \\
\text { nova faze do neoliberalismo }\end{array}$ & Link & 138 & - \\
\hline 03/05 & $\begin{array}{c}\text { Informativo; } \\
\text { Divulgação; } \\
\text { Ativista }\end{array}$ & $\begin{array}{c}\text { Leia o manifesto "Monopólio } \\
\text { é Golpe" na íntegra: http:// } \\
\text { tinyurl.com/h9euxxn }\end{array}$ & $\begin{array}{l}\text { Texto; } \\
\text { Imagem; } \\
\text { Link }\end{array}$ & 66 & \#MonopólioÉGolpe \\
\hline 05/05 & Ativista & $\begin{array}{c}\text { Monopólio das } \\
\text { comunicações é um } \\
\text { golpe na democracia. }\end{array}$ & $\begin{array}{c}\text { Texto; } \\
\text { Imagem }\end{array}$ & 67 & \#GolpismoDaMídia \\
\hline $05 / 05$ & $\begin{array}{c}\text { Informativo; } \\
\text { Ativista }\end{array}$ & $\begin{array}{c}\text { Manifestante invade } \\
\text { link do SBT. }\end{array}$ & Link & 66 & \#GolpismoDaMídia \\
\hline $13 / 05$ & Ativista & $\begin{array}{l}\text { Sete dos } 23 \text { ministros } \\
\text { de Temer possuem ou } \\
\text { controlam rádio e TV. }\end{array}$ & Link & 114 & - \\
\hline 18/05 & Ativista & $\begin{array}{l}\text { EBC conquista do } \\
\text { povo: pluralidade. }\end{array}$ & $\begin{array}{l}\text { Texto; } \\
\text { Imagem; } \\
\text { Link }\end{array}$ & 78 & $\begin{array}{c}\text { \#EBCFforteAutônomaEDemocrática } \\
\text { \#EBC } \\
\text { \#ComunicaçãoPública }\end{array}$ \\
\hline 18/05 & Ativista & $\begin{array}{l}\text { EBC conquista do } \\
\text { povo: diversidade. }\end{array}$ & $\begin{array}{l}\text { Texto; } \\
\text { Imagem; } \\
\text { Link }\end{array}$ & 86 & $\begin{array}{c}\text { \#EBCFforteAutônomaEDemocrática } \\
\text { \#EBC } \\
\text { \#ComunicaçãoPública }\end{array}$ \\
\hline
\end{tabular}

Fonte: Os autores.

\section{Twitter}

O FNDC está presente na rede social do Twitter ${ }^{3}$ desde maio de 2010, acumulando até maio de 2016 um total de 10,4 mil tweets, 4.004 seguidores e seguindo 409 perfis dessa rede. Na página principal, não há nenhuma descrição sobre 0 que é 0 
fórum, existindo somente a definição da sigla FNDC. Além disso, encontra-se apenas o link de redirecionamento para o site do FNDC, sem fazer menção a qualquer outra mídia ou rede social, como o Facebook.

Durante o mês de análise foram coletados 159 tweets, somando 559 retweets (replicações do que foi escrito no perfil do fórum) e 437 curtidas. Assim como no Facebook, adotou-se como padrão coletar os dados e realizar os prints das telas sempre no fim de cada semana e, a partir disso, foi observada a mesma ausência de periodicidade no Twitter, uma vez que não houve uniformização na distribuição de posts durante a semana, sendo que em determinados dias chegaram em mais de 20 postagens e, em outros, zero.

De forma geral, constatou-se que o fórum não explorou os recursos que essa rede social possui para seu benefício, ou seja, para aumentar sua divulgação e interagir com a população, entre outros. Além disso, o perfil criado no Twitter aparentou existir apenas para acompanhar um padrão de outros órgãos e instituições. Isto é, o Twitter se tornou um espaço de publicações com ausência de gerenciamento de conteúdo e sem uso estratégico para motivar o ativismo, interagir com internautas, divulgar o FNDC etc. Ainda nesse quesito, percebeu-se que a maioria dos conteúdos expostos nessa rede social eram repostagens das publicações feitas no Facebook, ou seja, os conteúdos divulgados no Twitter não possuíam originalidade, tendo sido, em sua maioria, repostagens de outros veículos. Para aprofundar a discussão, apresenta-se um recorte das postagens que mais obtiveram retweets e curtidas ao longo de maio, conforme exibido na Tabela 3 , a seguir.

Tabela 3: FNDC - Postagens com mais retweets e curtidas no Twitter.

\begin{tabular}{|c|c|c|c|c|c|}
\hline Data & Fonte & Teor & Assunto & Retweets & Curtidas \\
\hline 04/05 & Site FNDC & $\begin{array}{c}\text { Divulgação } \\
\text { e ativista }\end{array}$ & $\begin{array}{c}\text { FNDC e Frente Brasil popular } \\
\text { convocam e organizam ato } \\
\text { contra o golpismo midiático. }\end{array}$ & 21 & 14 \\
\hline 1) $05 / 05$ & Site FNDC & $\begin{array}{l}\text { Informativo } \\
\text { e ativista. }\end{array}$ & $\begin{array}{c}\text { Porque o monopólio é } \\
\text { golpe (manifesto). }\end{array}$ & 44 & 29 \\
\hline 2) $05 / 05$ & Próprio Twitter FNDC & Ativista & Sem mídia democrática! & 98 & 89 \\
\hline 3) $05 / 05$ & $\begin{array}{c}\text { Retweet Marcha } \\
\text { das Mulheres }\end{array}$ & Ativista & \#GolpismoDaMídia & 26 & 20 \\
\hline 4) $05 / 05$ & Próprio Twitter FNDC & Ativista & $\begin{array}{c}\text { \#GolpismoDaMídia acaba } \\
\text { de entrar nos TTs. }\end{array}$ & 33 & 17 \\
\hline 5) $05 / 05$ & Próprio Twitter FNDC & Ativista & $\begin{array}{l}\text { Os Marinhos são a cara do } \\
\text { \#GolpismoDaMídia. }\end{array}$ & 19 & 17 \\
\hline
\end{tabular}




\begin{tabular}{|c|c|c|c|c|c|}
\hline Data & Fonte & Teor & Assunto & Retweets & Curtidas \\
\hline 6) $05 / 05$ & Retweet Coletivo FMD & Ativista & $\begin{array}{c}\text { Vasco e Botafogo: rivais na } \\
\text { final do carioca, unidos contra } \\
\text { o \#GolpismoDaMídia. }\end{array}$ & 18 & 13 \\
\hline
\end{tabular}

Fonte: Os autores.

Curiosamente, as sete postagens que receberam maior número de retweets e curtidas não estavam vinculadas a publicações feitas no Facebook, como a maioria das outras publicações, muitas das quais não tiveram nenhum retweet ou qualquer curtida. Duas delas redirecionavam o internauta para o site do FNDC, três eram mensagens adaptadas à própria linguagem do Twitter e duas eram retweets de outros perfis. Isso indica que a estratégia de utilizar o Twitter como uma forma de divulgação do que já foi exposto no Facebook não é eficiente; no entanto, quando as mensagens foram autênticas ao perfil do Twitter, a repercussão foi muito maior.

Ao considerar que um dos grandes destaques do Twitter é o uso das hashtags, ou seja, palavras-chave precedidas do símbolo do jogo da velha (\#), que, se muito utilizadas pelos internautas, aparecem nos trending topics (TTS) - um espaço reservado nessa rede social para destacar os assuntos mais comentados naquele momento por seus usuários -, pode-se indicar que 0 FNDC fez pouco uso estratégico desse recurso. Durante o período de análise, ele apenas fez uso de hashtags já existentes, como a que aparece na Tabela 3 (\#GolpismoDaMídia), a qual conseguiu entrar nos TTs, conforme indica a publicação do dia 05/05. Portanto, assim como se constatou no Facebook, as hashtags poderiam ser utilizadas no desenvolvimento de campanhas e para incentivar o ativismo, uma vez que geram uma alta disseminação, principalmente no Twitter, por possuir um espaço específico para a divulgação das hashtags mais mencionadas. As publicações de destaque em maio eram de textos com teor ativista, com críticas sobre a ausência de democracia na mídia e com o uso da hashtag "Golpismo da mídia", que, apesar de estar vinculada à causa do FNDC, não foi uma hashtag de sua iniciativa. Acredita-se que essas postagens receberam ênfase em função do momento político em que o país se encontrava naquele período.

De maneira geral, assim como aconteceu no Facebook, percebeu-se uma baixa presença de comentários e quase nula interação da página com os seus seguidores. Com isso, pode-se sugerir que, caso tivesse havido uma maior interação do FNDC com os usuários do Twitter, poderia ter ocorrido um crescimento na utilização do espaço de reply (respostas), curtidas e retweets por partes dos que seguem o perfil do fórum.

\section{Site e Youtube}

Como o presente trabalho se comprometeu em analisar as mídias e redes sociais do FNDC, esta parte da análise pôs o foco na aba do site que remetia ao e-fórum/notícias ${ }^{4}$. Na página de entrada foi possível encontrar uma parte reservada somente para os textos do e-fórum/notícias, onde as quatro últimas postagens repassam em sequência e permitem 0 acesso ao internauta. Aliás, este é o espaço de maior destaque do site, podendo-se sugerir que, na verdade, a aba nomeada de e-fórum/ notícias se assemelha às características de um blogeu.

4 Site <http://www.fndc.org.br/noticias/>. 
Ressalte-se também que na coluna direita do site existe um espaço reservado para indicar uma nuvem de tags, mostrar as atualizações do FNDC no Twitter e, abaixo, a opção de curtir a página deles no Facebook. Na cabeceira do site existem ícones que remetem ao Facebook, Twitter, Youtube e Flickr, ainda que, respectivamente, um não seja atualizado há mais de dois anos (em maio de 2016) e o outro não exista menção em mais nenhum outro ambiente virtual do fórum. Na parte de cima do portal, à direita, há um caixa para que o internauta se cadastre no site e receba notícias do FNDC no site.

Durante o período de análise, foram publicadas doze reportagens no e-fórum/notícias e, como ocorreu no Facebook e no Twitter, observou-se que não houve uma periodicidade nas publicações, assim como não existiu uma padronização na distribuição de postagens durante a semana, sendo que em determinados dias chegaram em três reportagens divulgadas, em outros, uma e na maioria, nenhuma.

A maioria das publicações possuía um caráter informativo sobre temáticas que envolvem a luta do FNDC, mas identificouse que, em duas das doze reportagens, o fórum se posicionou sobre determinado assunto e, em outras duas, fez a divulgação de eventos e atos de defesa. É importante ressaltar que não há espaço para comentários abaixo dos textos divulgados no site e que nem sempre as matérias são divulgadas em suas redes sociais. A partir disso, identifica-se uma interação nula nessa mídia e pode-se sugerir, assim como nas outras redes sociais, que, caso houvesse maior interação do FNDC com os interessados em acompanhar o fórum, poderia haver um crescimento de acesso ao site e de divulgação do FNDC em geral.

Em relação ao YouTube, ainda que existissem oito vídeos publicados e 21 inscritos no canal, em maio de 2016, o FNDC não atualizava essa mídia havia dois anos e, portanto, ela não foi analisada durante o período para a realização deste estudo.

\section{CONSIDERAÇÕES FINAIS}

0 trabalho de monitoramento das atividades do Fórum Nacional Pela Democratização da Comunicação (FNDC) nas mídias sociais do Facebook e do Twitter, bem como em seu próprio endereço eletrônico, possibilitou analisar a comunicação feita pelos próprios comunicadores e apresentou o movimento social como uma entidade que engloba muitos outros movimentos e grupos, e indicou que, muitas vezes, o FNDC acabou se voltando para as atividades de militância online.

As postagens do fórum na página do Facebook, assim como no Twitter, não pareciam seguir um padrão de atividades previstas para a gestão das mídias sociais. Por vezes, contabilizaram-se mais de duas dezenas de publicações por dia e em outros dias não houve qualquer atividade do FNDC na rede. É claro que um movimento social pode não ter a necessidade de atualizar suas mídias na internet diariamente, ou não ver como prioridade esse tópico na agenda organizativa, mas, não se pode negar que a falta de um comportamento unificado traz confusão àqueles que tentam acompanhar ou entender uma organização coletiva.

A ausência aparente de planejamento das ações do FNDC se destacou à medida que teve como consequência pouca repercussão das pautas do movimento dentro e fora das redes sociais. As ações, em sua maioria concentradas no Facebook e no Twitter, não tiveram engajamento expressivo dos usuários com os conteúdos publicados.

Também é significativo ressaltar o papel que as noções de "interação" e "compartilhamento" têm no contexto das mídias digitais. As redes sociais possuem um caráter bastante inovador de interação com o público de uma dada mensagem. Assim, deve-se aproveitar ao máximo as ferramentas disponibilizadas nas diferentes redes, de forma a de fato haver uma comunicação entre os movimentos e a população que tem acesso aos conteúdos compartilhados. No caso do FNDC, observou-se, por exemplo, pouca 
interação entre o movimento social e os usuários (estes raramente se engajavam com um conteúdo), seja compartilhando o que foi publicado ou mesmo comentando-0. Esses momentos de engajamento devem ser reforçados e não podem ser desperdiçados. É essencial que os movimentos sociais se organizem para responder a perguntas e comentários, incentivar 0 debate, 0 compartilhamento e a interação em torno dos temas propostos, de forma a disseminar suas pautas e demandas.

Além disso, cabe apontar a relevância de se considerarem as redes sociais utilizadas como lócus de atuação dos diferentes movimentos em seu contexto histórico, social e econômico. Isso significa que, para planejar ações com maiores chances de sucesso, é preciso considerar que os espaços digitais de atuação são regidos, assim como os espaços não digitais, por contingências econômicas e políticas, o que se manifesta nas ferramentas de interação disponibilizadas pelas redes sociais e no próprio funcionamento das mesmas. A questão do algoritmo, por exemplo, tem cada vez mais aparecido como pauta de debate em diferentes setores da sociedade, sendo, inclusive, fundamental para as pautas do FNDC, já que a discussão perpassa pela questão da democratização da comunicação, de ideias e vozes.

De forma geral, conclui-se que é fundamental o papel das redes sociais para o fortalecimento dos mais diferentes movimentos sociais. Além de contribuir para a união e o empoderamento dos sujeitos envolvidos, 0 ativismo online tem se destacado como importante representante na luta por transformações sociais. Em conjunto com ações devidamente planejadas em diferentes meios de comunicação e espaços, se torna um forte aliado dos movimentos, possibilitando uma forma de contracontrole inovadora, que, na medida do possível, se apresenta como uma alternativa diante do controle exercido pelos oligopólios midiáticos, pelo governo e por outras instituições.

Em relação às análises realizadas nas mídias e redes sociais do Fórum Nacional Pela Democratização da Comunicação, sugere-se que este não se mostra adequadamente inserido no ambiente virtual, uma vez que poucas das suas publicações obtiveram um grande retorno do público. Essa realidade indica um caminho a ser trilhado na mobilização e na conscientização dos cidadãos e das cidadãs para o fortalecimento do debate no Brasil.

\section{REFERÊNCIAS}

BANDEIRA, Denize Daudt. Os processos de comunicação e cidadania. Estudos, Goiânia, v. 38, n. 4, 2011. Disponível em: <http:// seer.ucg.br/index.php/estudos/article/viewFile/2327/1424>. Acesso em: 16/09/2016.

BORDENAVE, Juan E. Díaz. O que é participação. São Paulo: Brasiliense, 1983.

CASTELLS, Manuel. Redes de indignação e esperança: movimentos sociais na era da internet. Rio de Janeiro: Editora Zahar, 2013.

FNDC - Fórum Nacional pela Democratização da Comunicação. Quem somos. Disponível em: <http://www.fndc.org.br/ forum/quem-somos/>.

GOHN, Maria da Glória. Movimentos sociais na atualidade: manifestações e categorias analíticas. In: GOHN, Maria da Gloria (Org.). Movimentos sociais no início do século XXI: antigos e novos atores sociais. 3. ed. Petrópolis, RJ: Vozes, 2007.

HENRIQUES, Márcio Simeone. A dinâmica da comunicação para a mobilização social nas práticas da extensão universitária. Interfaces - Revista de Extensão, v. 1, n. 1, p. 24-34, jul./nov. 2013. 
HENRIQUES, Márcio Simeone; MAFRA, Rennan L. Martins. Estratégias comunicativas para a ação corresponsável: um estudo de caso. In: SIMPÓSIO DA PESQUISA EM COMUNICAÇÃO DA REGIÃO SUDESTE - VIII SIPEC. Vitória, 16-17 de março de 2001. Anais... São Paulo: Intercom, 2001.

LÉVY, Pierre. A inteligência coletiva: por uma antropologia do ciberespaço. São Paulo: Edições Loyola, 1994.

LUVIZOTTO, Caroline Kraus. Cidadania, ativismo e participação na internet: experiências brasileiras. Comunicação \& Sociedade, Universidade do Minho, v. 30, p. 297-312, 2016.

LUVIZOTTO, Caroline Kraus; SERIDORIO, Daniele Ferreira. Movimentos sociais, ativismo e participação na sociedade da informação. In: LUVIZOTTO, Caroline Kraus; LOSNAK, Célio José; ROTHBERG, Danilo. Mídia e sociedade em transformação. São Paulo: Cultura Acadêmica; Editora Unesp, 2016.

LUVIZOTTO, Caroline Kraus et al. Ativismo socioambiental on-line: uma análise do movimento "Uma gota no oceano". GEMInIS, v.7, p.75-100, 2016.

MORAES, Dênis de. Comunicação virtual e cidadania: movimentos sociais e políticos na internet. Revista Brasileira de Ciências da Comunicação, v. XXIII, n. 2, jul./dez. p. 142-155, 2000.

PEREIRA, Marcus A. Internet e mobilização política: os movimentos sociais na era digital. In: ENCONTRO DA COMPOLÍTICA, IV, abril de 2011, Rio de Janeiro. Anais... Rio de Janeiro, UERJ, 2011.

PERUZZO, Cicilia M. Krohling Movimentos sociais, redes virtuais e mídia alternativa no junho em que "o gigante acordou"? MATRIZes, São Paulo, v. 7, n. 2, p. 73-93, 2013.

SCHERER-WARREN, Ilse. Das mobilizações às redes de movimentos sociais. Sociedade e Estado, v. 21, n. 1, p. 109-130, 2006.

VALENTE, Carlos; MATTAR, João. Second life e web 2.0 na educação: o potencial revolucionário das novas tecnologias. São Paulo: Novatec Editora, 2007.

VICENTE, Maximiliano Martin. Comunicação e cidadania: tensões e complementaridades. In: VICENTE, Maximiliano Martin. (Org.). Mídia e sociedade. Bauru: Edusc, 2009.

\section{GLOSSÁRIO}

FANPAGE - Página de fãs é uma página específica dentro do Facebook direcionada para empresas, marcas ou produtos, associações, sindicatos, autônomos, ou seja, qualquer organização com ou sem fins lucrativos que desejem interagir com os seus clientes no Facebook. (Disponível em: <https://aldabra.com.br/artigo/o-que-e-uma-fanpage>).

GIF - Graphics interchange format ou formato de intercâmbio de gráficos é um formato de imagem muito usado na internet, lançado em 1987 pela CompuServe, para disponibilizar um formato de imagem com cores em substituição do formato RLE, que era apenas preto e branco. (Disponível em: <http://www.techtudo.com.br/artigos/noticia/2012/04/0-que-e-gif.html>).

HASHTAG-Éuma expressão comumentre os usuários das redes sociais na internet. Consiste de uma palavra-chave antecedida pelo símbolo "\#", conhecido popularmente no Brasil por "jogo da velha" ou "quadrado". Geralmente essas hashtags tornamse links indexáveis pelos mecanismos de busca. Isso permite que os demais usuários possam clicar nelas ou procurá-las e 
visualizar todas as informações, imagens, vídeos etc. relacionados a elas. (Disponível em: <https://canaltech.com.br/0-quee/o-que-e/0-que-e-hashtag/> e <https://www.significados.com.br/hashtag/>).

HOME DO PORTAL - Segundo definição do Google, é a página principal, de abertura de um site (ou rede social), através da qual o programa navegador, uma vez indicado o seu endereço (URL), tem acesso ao referido site.

PRINT / PRINT SCREEN - É uma tecla comum nos teclados de computador. No Windows, quando a tecla é pressionada, ela captura em forma de imagem tudo o que está presente na tela (exceto o ponteiro do mouse e vídeos) e o copia para a área de transferência. (Disponível em: <https://pt.wikipedia.org/wiki/Print_screen>).

POST -É o mesmo que postagem - o ato de postar, de enviar ou colocar algo no correio para que seja expedido para determinado destino. No âmbito dos meios de comunicação online, o termo postagem é utilizado como sinônimo de publicação, ou seja, quando algum conteúdo é compartilhado nas redes sociais ou em outra plataforma digital com acesso à internet, por exemplo. (Disponível em: <https://www.significados.com.br/postagem/>).

NUVEM DE TAGS - Nuvem de tags, nuvem de palavras ou nuvem de etiquetas é uma lista hierarquizada visualmente, uma forma de apresentar os itens de conteúdo de um website. (Disponível em: <https://pt.wikipedia.org/wiki/Nuvem_de_tags>).

REPLY - Forma de interagir na rede social online Twitter. 0 reply é uma resposta pública de um usuário para outro, a partir de um tweet.

RETWEET(S) (Abrev. "RT") - Forma de interagir na rede social online Twitter. 0 retweet é o compartilhamento público realizado por um usuário em seu perfil em relação ao tweet de outro usuário.

TRENDING TOPICS (Abrev. "TTS") - É um recurso que mede a popularidade de assuntos no Twitter. A tradução ao pé da letra de trending topic (TT) é "tópico em tendência". Mas o termo usado na versão em português, "assuntos do momento", explica melhor o conceito. (Disponível em: <http://tecnologia.ig.com.br/o-que-sao-e-como-funcionam-os-trending-topics/ n1597175643026.html>).

TWEET(S) - É o termo utilizado para designar as publicações com no máximo 140 caracteres, feitas na rede social do Twitter. (Disponível em: <https://www.significados.com.br/tweet/>).

Texto recebido em 30.03.2017 e aprovado em 30.05.2017. 